Int. J. Electrochem. Sci., 12 (2017) $11181-11194$

International Journal of

ELECTROCHEMICAL

SCIENCE

www.electrochemsci.org

\title{
A Silver Hexacyanoferrate-Graphene Modified Glassy Carbon Electrode in Electrochemical Sensing of Uric Acid and Dopamine
}

\author{
Fenghua Zhang ${ }^{1}$, Sue $\mathrm{Li}^{1}$, Hua Zhang ${ }^{1,2}$, Huaixiang $\mathrm{Li}^{1,{ }^{*}}$ \\ ${ }^{1}$ College of Chemistry, Chemical Engineering and Materials Science, Collaborative Innovation Center \\ of Functionalized Probes for Chemical Imaging in Universities of Shandong, Key Laboratory of \\ Molecular and Nano Probes, Ministry of Education, Shandong Provincial Key Laboratory of Clean \\ Production of Fine Chemicals, Shandong Normal University, Jinan 250014, P. R. China \\ ${ }^{2}$ School of Materials Science and Engineering, Shandong University of Technology, Zibo 255000, P.R. \\ China \\ "E-mail: lihuaixaing@sdnu.edu.cn
}

doi: $10.20964 / 2017.12 .13$

Received: 7 August 2017 / Accepted: 10 October 2017 / Published: 12 November 2017

A silver hexacyanoferrate-graphene hybrid modified glassy carbon electrode is put forward in sensing of uric acid (UA) and dopamine (DA) in this work. The structure and composition of the silver hexacyanoferrate was characterized by X-ray diffraction (XRD) and X-ray photoelectron spectroscopy (XPS). Catalysis of the modified material to the electrochemical reaction of UA and DA were verified by cyclic amperometry method. Experiments show that both UA and DA have excellent linear response on the modified electrode in acetic acid buffer solution by chronoamperometry measurements. The sensitivity is $0.102 \mu \mathrm{A} / \mu \mathrm{M}$ in linear range of 2-80 $\mu \mathrm{M}$ UA with a detection limit of $0.07 \mu \mathrm{M}$ and the sensitivity DA is $0.133 \mu \mathrm{A} / \mu \mathrm{M}$ in the range of $0.4-28 \mu \mathrm{M}$ DA with a detection limit of $0.03 \mu \mathrm{M}$. Furthermore, the developed sensor exhibited a high sensitivity, good reproducibility, stability for the detection of UA and DA.

Keywords: dopamine; uric acid; electrochemical sensor; graphene; silver hexacyanoferrate

\section{$\underline{\text { FULL TEXT }}$}

(C) 2017 The Authors. Published by ESG (www.electrochemsci.org). This article is an open access article distributed under the terms and conditions of the Creative Commons Attribution license (http://creativecommons.org/licenses/by/4.0/). 